\title{
Effect of Ammonium- and Potassium-Loaded Zeolite on Kale (Brassica alboglabra) Growth and Soil Property
}

\author{
Junxi Li ${ }^{1,2^{*}}$, Chido Wee ${ }^{1}$, Bokyoon Sohn ${ }^{1}$ \\ ${ }^{1}$ Department of Agricultural Chemistry, Sunchon National University, Suncheon, South Korea; ${ }^{2}$ School of Biology and Biotechnol- \\ ogy Sciences, Murdoch University, Perth, Australia. \\ Email: junxi1981@gmail.com
}

Received August $1^{\text {st }}, 2013$; revised September $5^{\text {th }}, 2013$; accepted September $23^{\text {rd }}, 2013$

Copyright (C) 2013 Junxi Li et al. This is an open access article distributed under the Creative Commons Attribution License, which permits unrestricted use, distribution, and reproduction in any medium, provided the original work is properly cited.

\begin{abstract}
We investigated the feasibility of using ammonium- and potassium-loaded zeolite (NK-Z) as carriers for fertilizer and for slow release of nitrogen $(\mathrm{N})$ and potassium $(\mathrm{K})$. Plant growth response and soil analysis were performed. The results indicated an increase in the total harvest weight of kale (Brassica alboglabra Bailey). Furthermore, higher levels of $\mathrm{N}$ and $\mathrm{K}$ were detected in soil applied with NK-Z than in soil applied with compound fertilizers. The leaf fresh weight of kale in the fertilizer treatments including NK-Z were 2118.4 and $2111.3 \mathrm{~g} \cdot$ plant $^{-1}$, while the leaf fresh weights of kale in the treatment without NK-Z was $2018.0 \mathrm{~g} \cdot$ plant $^{-1}$. The $\mathrm{N}$ and K contents in the soils were maintained in the high level in the NK-Z treatment compared that in control treatment. The results indicate that NK-Z has a great potential as the slow-release fertilizer reducing pollution by preventing leaching to the ground water.
\end{abstract}

Keywords: Zeolite; Slow-Release Fertilizer; Soil Property; Kale; Growth Response

\section{Introduction}

Zeolites have been used in commercial applications because of their unique adsorption, ion-exchange, molecular sieve, and catalytic properties. In agricultural field, natural zeolite can be provided in large quantities with uniform characteristics and unique properties (cation exchange capacity and $\mathrm{pH}$ ) for application and commercial processing [1]. The negative charge created when $\mathrm{Al}^{3+}$ replaces $\mathrm{Si}^{4+}$ in structural tetrahedra is counterbalanced by cations (e.g., $\mathrm{Na}^{+}, \mathrm{K}^{+}, \mathrm{NH}_{4}^{+}$, and $\mathrm{Ca}^{2+}, \mathrm{Mg}^{2+}$ ). These charge sites are located in large structural channels and cavities throughout the structure and will be referred to as zeolitic exchange sites. Due to this special structure, natural zeolite can adsorb many kinds of ions with varying degrees of ability. Natural zeolite is highly selective for $\mathrm{NH}_{4}^{+}$and $\mathrm{K}^{+}$relative to $\mathrm{Na}^{+}$or divalent cations such as $\mathrm{Ca}^{2+}$ and $\mathrm{Mg}^{2+}$ due to the location and density of negative charge in the structure and the dimensions of interior channels (0.40 - $0.72 \mathrm{~nm}$ diameter) [2].

Natural zeolites in soil help to retain nutrients and improve long-term soil quality by enhancing its absorption ability. It influences soil retention of the most important plant nutrients such as $\mathrm{N}$ and $\mathrm{K}, \mathrm{Ca}, \mathrm{Mg}$, and many kinds

"Corresponding author. of micro-elements. Zeolite can retain these nutrients in the root zone to be used by plants as needed. The application of natural zeolite also enhances plant growth and reduces nutrient loss. Many laboratory and field experiments carried in recent decades have shown that surfactant-modified zeolite and nutrient-loaded zeolite can be used as a kind of slow-release fertilizer to supply longlasting nutrients for crop growth $[3,4]$. The application of zeolite can enhance the plant growth and development by reducing the loss of nutrients. The main use of natural zeolites in agriculture is for ammonium $\left(\mathrm{NH}_{4}^{+}\right)$exchange, storage, slow release and decrease losses of nitrogen through nitrification.

Nitrogen leaching from irrigated cropland significantly contributes to increased nitrate $\left(\mathrm{NO}_{3}^{-}\right)$levels in ground and surface water [5]. To overcome the problems associated with nitrogen leaching during fertilizer application, different approaches were taken to control $\mathrm{N}$ release. Generally, slow-release fertilizers (SRF) are usually expensive, and the release of $\mathrm{N}$ is slow at the time of high $\mathrm{N}$ need. However, in a 4-week long experiment, Perrin et al. [6] reported that soil amendment with ammonium-loaded clinoptilolite (A-CP) significantly reduced leaching and provided sufficient $\mathrm{N}$ for normal corn growth. However, corn begins to take up exponentially higher levels of $\mathrm{N}$ 
approximately 4 weeks after emergence [7]. Thus, Perrin et al. did not analyze whether A-CP released sufficient amounts of $\mathrm{N}$ to meet the $\mathrm{N}$ requirement of corn during the entire growth period.

Kale (Brassica alboglabra Bailey) is one of the most commonly grown vegetables in South Korea. The purpose of this study was to investigate the growth characteristics of kale and the feasibility of using NK-Z as carriers for fertilizer and for slow release of $\mathrm{N}$ and $\mathrm{K}$.

\section{Materials and Methods}

\subsection{Zeolite}

Natural zeolites used in this experiment were purchased from Handu Co. Korea at a size of $1-2 \mathrm{~mm}$ in diameter. The constitution of the natural zeolite used in this experiment is shown in Table 1. The natural zeolite mainly consisted of $\mathrm{SiO}_{2}$ and $\mathrm{Al}_{2} \mathrm{O}_{3}$, which comprised $70.3 \%$ and $13.6 \%$ of the total elements. Because of the high cation exchange capacity (CEC), this kind of natural zeolite is a good carrier for cation. The zeolite layer was collected from the bottom of the autoclave during the hydrothermal process, and the structure was characterized using X-ray diffraction (XRD, D/Max-2500V/PC, PANalytical B.V.) analysis. The natural zeolites used in this experiment were confirmed as Mordenite (33\%), Muscovite (37\%) and Clinoptilolite (30\%).

\subsection{Production of Ammonium- and Potassium-Loaded Zeolite}

Ammonium-loaded zeolite (NZ) and potassium-loaded zeolite (KZ) were produced using the method of Perrin et al. [4] with minor modification. Natural zeolite particles were loaded with $\mathrm{NH}_{4}^{+}$and $\mathrm{K}^{+}$by soaking in $1 \mathrm{M}$ ammonium sulfate $\left(\left(\mathrm{NH}_{4}\right)_{2} \mathrm{SO}_{4}\right)$ and $1 \mathrm{M}$ potassium chloride $(\mathrm{KCl})$, respectively, for 10 days. $\mathrm{NZ}$ and $\mathrm{KZ}$ were rinsed with water until the electrical conductivity (EC) of the supernatant was $<0.5 \mathrm{mSm}^{-1}$ [4]. Total $\mathrm{N}$ content in $\mathrm{NZ}$ was analyzed using the Kjeldahl digestion method [8], and Total $\mathrm{K}$ content in $\mathrm{KZ}$ was analyzed using inductive coupled plasma-mass spectrometry (ICP, Optima 3300 DV, Perkin-Elmer, USA). The NZ and KZ fertilizers (NK-Z) so produced contained $2 \% \mathrm{~N}$ and $3 \% \mathrm{~K}$, respectively.

\subsection{Tested Crops and Farming Methods}

Kale (Brassica alboglabra Bailey) was selected as the test plant and cultured as seedlings in a greenhouse. The characteristics of soil and the kale were tested before the kale transplanting (Tables 2 and 3). Approximately 200 $\mathrm{kg} / 10 \mathrm{a}$ lime and $1500 \mathrm{~kg} / 10 \mathrm{a}$ compost were mixed in the soil because of the low fertility of the soil. In each treatment, the compound fertilizer or NK-Z was broadcasted on the field uniformly and mixed with the soil using cultivator.

The growth characteristics of kale and changes in nitrogen and potassium concentrations in soil were investigated regularly after application of NK-Z. Three kinds of fertilizers were used in this experiment: (1) compound fertilizer as basal conventional fertilizer along with additional fertilizer (CF), (2) compound fertilizer as the basal conventional fertilizer and $\mathrm{NK}-Z$ as the additional fertilizer (ZAF), and (3) NK-Z as the basal and additional fertilizer (ZBAF). The concentrations of N, P and $\mathrm{K}$ between compound fertilizer and NK-Z fertilizer had no differences among every treatments. The experiment area for every treatments were $2.4 \mathrm{~m}^{2}, 100 \mathrm{~g}$ compound fertilizer (N-P-K $=11-10-8 \mathrm{~kg} / 10 \mathrm{a})$ were added into the soil in the treatment of CF. In the treatment of ZAF, $100 \mathrm{~g}$ compound fertilizer (N-P-K $=11-10-8 \mathrm{~kg} / 10 \mathrm{a}$ ) were added into the soil as conventional fertilizer, $1425 \mathrm{~g} \mathrm{~N}-\mathrm{Z}$ and $263 \mathrm{~g} \mathrm{~K}-\mathrm{Z}$ were added as additional fertilizer, NK-Z as additional fertilizer were added into the soil at the same time with the application of basal fertilizer before seedling transplanting. In the treatment of ZBAF, the NK-Z were also added into the soil before seedling transplanting. $2200 \mathrm{~g} \mathrm{~N}-\mathrm{Z}, 405 \mathrm{~g} \mathrm{~K}-\mathrm{Z}$, and $36 \mathrm{~g}$ superphosphate (P $=20 \%$ ) were added into soil as basal and additional fertilizer.

Table 1. Chemical characteristics of natural zeolite used in the experiment.

\begin{tabular}{cccccccccc}
\hline $\begin{array}{c}\mathrm{SiO}_{2} \\
(\%)\end{array}$ & $\begin{array}{c}\mathrm{Al}_{2} \mathrm{O}_{3} \\
(\%)\end{array}$ & $\begin{array}{c}\mathrm{Fe}_{2} \mathrm{O}_{3} \\
(\%)\end{array}$ & $\begin{array}{c}\mathrm{CaO} \\
(\%)\end{array}$ & $\begin{array}{c}\mathrm{MgO} \\
(\%)\end{array}$ & $\begin{array}{c}\mathrm{Na}_{2} \mathrm{O} \\
(\%)\end{array}$ & $\begin{array}{c}\mathrm{K}_{2} \mathrm{O} \\
(\%)\end{array}$ & $\begin{array}{c}\mathrm{P}_{2} \mathrm{O}_{5} \\
(\%)\end{array}$ & $\begin{array}{c}\mathrm{Moisture} \\
(\%)\end{array}$ & $\begin{array}{c}\mathrm{Specific} \\
\text { gravity }\end{array}$ \\
\hline 70.3 & 13.6 & 1.29 & 2.51 & 0.31 & 1.93 & 3.17 & 0.09 & 6.80 \\
\hline
\end{tabular}

Table 2. The characteristics of experimental soil.

\begin{tabular}{|c|c|c|c|c|c|c|c|}
\hline \multirow{2}{*}{$\begin{array}{c}\mathrm{pH} \\
(1: 5)\end{array}$} & \multirow{2}{*}{$\begin{array}{c}\mathrm{EC} \\
\left(\mathrm{dSm}^{-1}\right)\end{array}$} & \multirow{2}{*}{$\begin{array}{c}\text { O.M } \\
\left(\mathrm{g} \cdot \mathrm{kg}^{-1}\right)\end{array}$} & \multirow{2}{*}{$\begin{array}{c}\mathrm{Av} \cdot \mathrm{P}_{2} \mathrm{O}_{5} \\
\left(\mathrm{mg} \cdot \mathrm{kg}^{-1}\right)\end{array}$} & \multicolumn{3}{|c|}{$\begin{array}{l}\text { Ex. Cations } \\
\left(\mathrm{cmol}^{+} \mathrm{kg}^{-1}\right)\end{array}$} & \multirow{2}{*}{$\begin{array}{c}\text { C.E.C } \\
\left(\mathrm{cmol}^{+} \mathrm{kg}^{-1}\right.\end{array}$} \\
\hline & & & & $\mathrm{K}$ & $\mathrm{Ca}$ & $\mathrm{Mg}$ & \\
\hline 5.7 & 0.81 & 28 & 643 & 1.8 & 4.9 & 2.1 & 10.8 \\
\hline
\end{tabular}


Table 3. The growth characteristics of kale before transplanting.

\begin{tabular}{cccc}
\hline Species & $\begin{array}{c}\text { No. of } \\
\text { leaves (ea) }\end{array}$ & $\begin{array}{c}\text { Leaf } \\
\text { area }\left(\mathrm{cm}^{2}\right)\end{array}$ & $\begin{array}{c}\text { Shoot } \\
\text { fresh weight }(\mathrm{g})\end{array}$ \\
\hline $\begin{array}{c}\text { Brassica alboglabra } \\
\text { Bailey }\end{array}$ & $5.0 \pm 0.0$ & $112.25 \pm 1.96$ & $8.02 \pm 0.26$ \\
\hline
\end{tabular}

\subsection{Test Methods and Statistical Analysis}

Soil in the different treatment fields were sampled $0,3,6$, and 18 weeks after transplanting, Weight $5 \mathrm{~g}$ dry soil into a plastic triangular flask, add $50 \mathrm{ml}$ distilled water and shake for 30 minutes at the speed of $120 \mathrm{rpm}$. The clear solution was accepted after filtering using what man No.2 filter paper. The nitrogen content was analyzed by the Kjeldahl digestion method [8] and potassium was analyzed by Inductive Coupled Plasma (ICP, Optima 3300 DV, Perkin-Elmer, USA) using the method of NIAST [9]. EC and $\mathrm{pH}$ were analyzed using Istek Conductivity meter and Mettler Toledo $340 \mathrm{pH}$ meter, respectively. Phosphorus and Soil CEC were also analyzed using the method of NIAST [9].

Chlorophyll content of fully expanded kale leaves was measured using an in situ SPAD-502 chlorophyll meter (Minolta Co. Ltd., Japan). Actual chlorophyll content Y $\left(\mathrm{mg} / 100 \mathrm{~cm}^{2}\right)$ was calculated by substituting the SPAD reading for $\mathrm{X}$ in the standard formula $\mathrm{Y}=0.0996 \mathrm{X}-$ 0.152 [10]. Leaf length and leaf width were measured using vernier caliper, shoot weight were measured using platform balance (A\&D HF-2000 g). For chemical analysis, plant samples were finely ground after drying at $65^{\circ} \mathrm{C}$ for $48 \mathrm{~h}$. A $0.5 \mathrm{~g}$ sample was placed in a $100 \mathrm{ml}$ flask with $10 \mathrm{ml}$ of concentrated $\mathrm{H}_{2} \mathrm{SO}_{4}$. Next, $0.5 \mathrm{ml} \mathrm{H} \mathrm{H}_{2}$ was added to the sample every $10 \mathrm{~min}$ for $90 \mathrm{~min}$ (total: $4.5 \mathrm{ml}$ ). After cooling, the solution was filtered through a Whatman No. 6 filter into $100 \mathrm{ml}$ flasks. Inorganic constituents contents were determined using Inductive Coupled Plasma (ICP, Optima 3300DV, Perkin-Elmer, USA). The data from different treatment combinations were analyzed using SPSS for windows.

\section{Results and Discussion}

\subsection{Crop Growth Characteristics}

Significant increases in the yields of wheat $(13 \%-15 \%)$, eggplant (19\% - 55\%), apples $(13 \%$ - 38\%), and carrots $(63 \%)$ were reported when $4-8$ tons of zeolite were added per acre [11]. In our study, leaf number, leaf length, leaf width, shoot weight, and chlorophyll content were estimated three weeks after transplanting (Table 4). The leaf length of kale in ZAF and ZBAF were $12.61 \%$ and $9.28 \%$ longer, respectively, than in CF. However, the leaf number did not differ significantly among the groups. The shoot weight in ZAF and ZBAF was $3.74 \%$ and
$3.61 \%$ higher, respectively, than in CF. Thus, the results indicate that $\mathrm{NK}-\mathrm{Z}$ enhances plant growth during the early stage.

The leaf fresh weight per plant was estimated at 6 intervals of harvesting. NK-Z improved the harvest of kale significantly; the yield in ZAF and ZBAF was $4.97 \%$ and 4.65\% higher, respectively, as compared with CF (Figure 1). It has been reported that leaf area, dry weight, and root fresh weight was higher in radishes fertilized with A-CP than in those fertilized with ammonium sulfate [12]. In this experiment, we showed that plant growth and kale harvest was higher both in ZAF and ZBAF as compared to that in $\mathrm{CF}$.

\subsection{Inorganic Matter Contents in Kale Leaf}

There was rare experiment adjustment the effective of zeolite on crop inorganic matter contents. In this paper, we tested the inorganic matter contents between every group in the kale leaf to investigate the effective of nutrition loaded zeolite on improving crop inorganic matter contents 18 weeks after transplanting (Table 5). In the group of ZAF, all of the tested inorganic constituents

Table 4. Growth responses of kale 3 weeks after transplanting.

\begin{tabular}{cccccc}
\hline Treatments & $\begin{array}{c}\text { No. of } \\
\text { leaves } \\
(\mathrm{ea})\end{array}$ & $\begin{array}{c}\text { Shoot } \\
\text { weight } \\
(\mathrm{g} / \mathrm{plant})\end{array}$ & $\begin{array}{c}\text { Leaf } \\
\text { length } \\
(\mathrm{cm})\end{array}$ & $\begin{array}{c}\text { Leaf } \\
\text { width } \\
(\mathrm{cm})\end{array}$ & $\begin{array}{c}\text { Chlorophyll } \\
\text { contents } \\
\left(\mathrm{mg} / 100 \mathrm{~cm}^{2}\right)\end{array}$ \\
\hline $\mathrm{CF}^{*}$ & 9.58 & 141.24 & 19.83 & 18.50 & 4.67 \\
$\mathrm{ZAF}^{*}$ & 9.41 & 146.52 & $22.33^{*}$ & 19.67 & 4.89 \\
$\mathrm{ZBAF}^{*}$ & 9.69 & 146.34 & 21.67 & 19.33 & 4.92 \\
$\mathrm{LSD}_{0.05}{ }^{*}$ & 0.379 & 25.971 & 1.972 & 2.568 & 0.386 \\
\hline
\end{tabular}

${ }^{*} \mathrm{CF}$, Compound fertilizer as basal conventional fertilizer along with additional fertilizer; ${ }^{*} \mathrm{ZAF}$, Compound fertilizer as basal conventional fertilizer, $\mathrm{NK}-\mathrm{Z}$ as additional fertilizer; ${ }^{*} \mathrm{ZBAF}, \mathrm{NK}-\mathrm{Z}$ as basal and additional fertilizer. "Each value was compared with least significant difference (LSD).

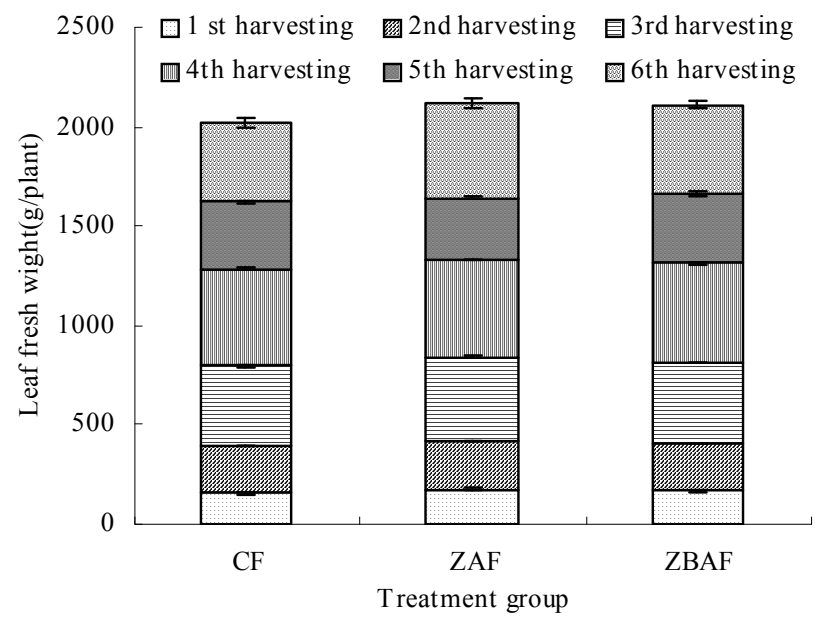

Figure 1. The fresh weight of kale leaf via 6 times of harvesting. 
contents $\left(\mathrm{CaO}, \mathrm{K}_{2} \mathrm{O}, \mathrm{MgO}, \mathrm{Na}_{2} \mathrm{O}\right)$ in kale leaf were significantly higher than that in the group of $\mathrm{CF}$, especially the $\mathrm{Na}_{2} \mathrm{O}$ content which was $50 \%$ higher than $\mathrm{CF}$. In the group of $\mathrm{ZBAF}$, the $\mathrm{K}_{2} \mathrm{O}, \mathrm{MgO}$ and $\mathrm{Na}_{2} \mathrm{O}$ contents were remarkably higher than that in the treatment of $\mathrm{CF}$. From the data above, we indicated that both ZAF and ZBAF improved the contents of inorganic constituents in kale leaf.

\subsection{The Physicochemical Property Change of Soil}

The addition of zeolites usually increases pH levels [13]. However, in this experiment, there were no significant differences between compound fertilizer and NK-Z fertilizer on the soil $\mathrm{pH}$ (Table 6). Available phosphorus (av-P) contents of CF group were $655.49 \mathrm{mg} \cdot \mathrm{kg}^{-1}$ before experiment and was $494.78 \mathrm{mg} \cdot \mathrm{kg}^{-1}$ at the end of the experiment. However, in ZBF group. The av-P contents were $516.03 \mathrm{mg} \cdot \mathrm{kg}^{-1}$ after the experiment. That because NK-Z, as a kind of slow-release fertilizer, could adsorb $P$ and release to soil slowly when crop needed, which lead to the less losing of $\mathrm{P}$.

CEC and exchangeable cation contents $\left(\mathrm{Ca}^{2+} \mathrm{K}^{+} \mathrm{Mg}^{2+}\right.$ $\mathrm{Na}^{+}$) in soil were analyzed in the last stage of plant growth (Table 7). The exchangeable cation contents and CEC had no significant differences among the three treatments. This was probably because of the same nutrients and the same cultivator methods were used in every treatment. The results indicate that NK-Z had no significant differences with the traditional chemical fertilizers on improving exchangeable cation contents and soil CEC. But the utility of NK-Z as a slow-release fertilizer on reducing the leaching speed of nitrogen and potassium was very important and would be discussed in the following.

\subsection{Nitrogen and Potassium Movement in Soil}

The dynamics of exchangeable and water-soluble $\mathrm{NH}_{4}-\mathrm{N}$ in soil is shown in Figure 2. During the first 3 weeks, the downward trend of exchangeable and water-soluble $\mathrm{NH}_{4}$ $\mathrm{N}$ was more apparent in the ZAF and ZBAF treatment group than in $C F$ treatment group, probably because of an absence of additional compound fertilizer in the former groups. A significant difference was observed in the $\mathrm{NH}_{4}-\mathrm{N}$ concentration among the various amendment treatments at all sampling dates, and the exchangeable $\mathrm{NH}_{4}-\mathrm{N}$ concentrations for all groups were less than $200 \mathrm{mg} \cdot \mathrm{kg}^{-1}$, 6 weeks after incubation. Eighteen weeks after transplanting ZAF and ZBAF applied soils appeared to maintain relatively higher $\mathrm{NH}_{4}-\mathrm{N}$ concentrations. This was probably due to retention of $\mathrm{NH}_{4}^{+}$on cation-exchange sites of the zeolite. The exchangeable $\mathrm{NH}_{4}-\mathrm{N}$ concentrations in ZAF and ZBAF were $8.22 \%$ and $45.40 \%$ higher, respectively, than in $\mathrm{CF}$, while water-soluble $\mathrm{NH}_{4}-\mathrm{N}$ concentrations in ZAF and ZBAF were $1.71 \%$ and $5.95 \%$ higher, respectively, than in $\mathrm{CF}$.

During the first 3 weeks, the downward trend in the exchangeable and water-soluble $\mathrm{NO}_{3}-\mathrm{N}$ concentrations

Table 5. Inorganic constituents contents in kale leaf 18 weeks after transplanting.

\begin{tabular}{ccccc}
\hline Treatments & $\begin{array}{c}\mathrm{CaO} \\
(\%)\end{array}$ & $\begin{array}{c}\mathrm{K}_{2} \mathrm{O} \\
(\%)\end{array}$ & $\begin{array}{c}\mathrm{MgO} \\
(\%)\end{array}$ & $\begin{array}{c}\mathrm{Na}_{2} \mathrm{O} \\
(\%)\end{array}$ \\
\hline $\mathrm{CF}^{*}$ & 2.40 & 1.10 & 0.39 & 0.18 \\
$\mathrm{ZAF}^{*}$ & $2.59^{*}$ & $1.29^{*}$ & $0.46^{*}$ & $0.27^{*}$ \\
$\mathrm{ZBAF}^{*}$ & 2.43 & $1.34^{*}$ & $0.46^{*}$ & $0.24^{*}$ \\
$\mathrm{LSD}_{0.05}^{*}$ & 0.073 & 0.049 & 0.013 & 0.009 \\
\hline
\end{tabular}

${ }^{*} \mathrm{CF}$, Compound fertilizer as basal conventional fertilizer along with additional fertilizer; *ZAF, Compound fertilizer as basal conventional fertilizer, $\mathrm{NK}-\mathrm{Z}$ as additional fertilizer; ${ }^{*} \mathrm{ZBAF}, \mathrm{NK}-\mathrm{Z}$ as basal and additional fertilizer. *Each value was compared with least significant difference (LSD).

Table 6. The physicochemical property changement of soil.

\begin{tabular}{|c|c|c|c|c|c|c|c|c|c|}
\hline & \multicolumn{3}{|c|}{$\mathrm{pH}$} & \multicolumn{3}{|c|}{$\mathrm{EC}\left(\mathrm{dS} \mathrm{m^{-1 } )}\right.$} & \multicolumn{3}{|c|}{ av-P2O5 $\left(\mathrm{mg} \cdot \mathrm{kg}^{-1}\right)$} \\
\hline & $\mathrm{CF}$ & $\mathrm{ZBF}$ & $\mathrm{ZBAF}$ & $\mathrm{CF}$ & $\mathrm{ZBF}$ & ZBAF & $\mathrm{CF}$ & $\mathrm{ZBF}$ & $\mathrm{ZBAF}$ \\
\hline Before & 6.70 & 6.68 & 6.66 & 0.58 & 0.58 & 0.56 & 655.49 & 618.94 & 621.05 \\
\hline After & 6.57 & 6.57 & 6.55 & 0.56 & 0.57 & 0.55 & 494.78 & 516.03 & 478.66 \\
\hline
\end{tabular}

Before: Soils sampled before experiment; After: Soils sampled after experiment.

Table 7. Exchangeable cation contents and cation exchange capacity in soil.

\begin{tabular}{cccccc}
\hline Treatments & $\begin{array}{c}\mathrm{Ca} \\
\left(\mathrm{cmol}^{+} \mathrm{kg}^{-1}\right)\end{array}$ & $\begin{array}{c}\mathrm{K} \\
\left(\mathrm{cmol}^{+} \mathrm{kg}^{-1}\right)\end{array}$ & $\begin{array}{c}\mathrm{Mg} \\
\left(\mathrm{cmol}^{+} \mathrm{kg}^{-1}\right)\end{array}$ & $\begin{array}{c}\mathrm{Na} \\
\left(\mathrm{cmol}^{+} \mathrm{kg}^{-1}\right)\end{array}$ & $\begin{array}{c}\mathrm{CEC} \\
\left(\mathrm{cmol}^{+} \mathrm{kg}^{-1}\right)\end{array}$ \\
\hline $\mathrm{CF}^{*}$ & 3.08 & 0.60 & 0.22 & 4.75 & 14.21 \\
$\mathrm{ZAF}^{*}$ & 3.32 & 0.59 & 0.20 & 5.03 & 14.49 \\
$\mathrm{ZBAF}^{*}$ & 3.07 & 0.57 & 0.19 & 4.81 & 14.71 \\
$\mathrm{LSD}_{0.05}{ }^{*}$ & 0.206 & 0.013 & 0.008 & 0.239 & 0.582 \\
\hline
\end{tabular}

${ }^{*} \mathrm{CF}$, Compound fertilizer as basal conventional fertilizer along with additional fertilizer; ${ }^{*} \mathrm{ZAF}$, Compound fertilizer as basal conventional fertilizer, NK-Z as additional fertilizer; ${ }^{*} \mathrm{ZBAF}, \mathrm{NK}-\mathrm{Z}$ as basal and additional fertilizer. ${ }^{*}$ Each value was compared with least significant difference (LSD). 


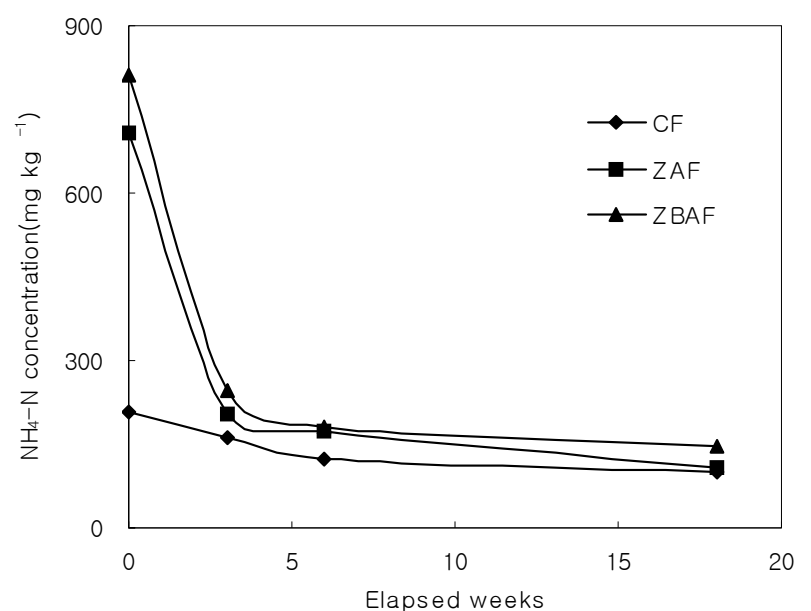

(a)

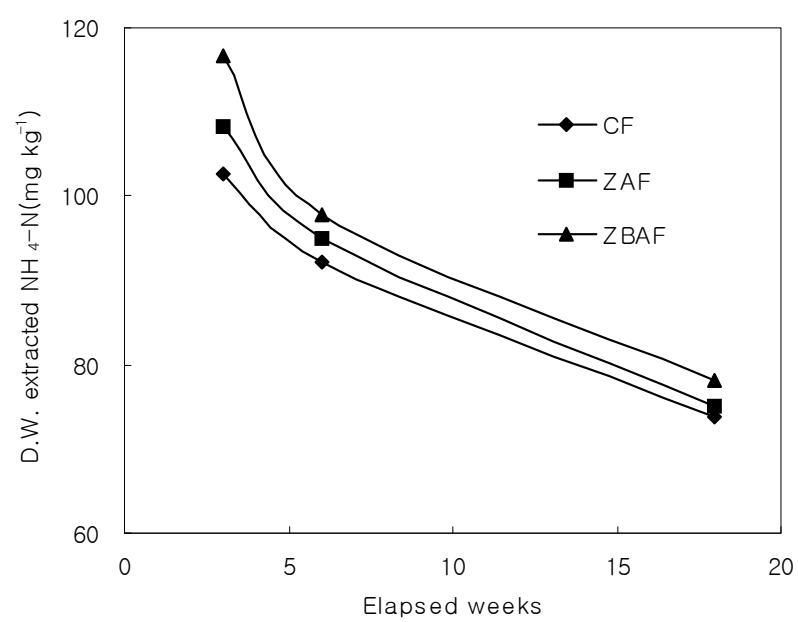

(b)

Figure 2. The dynamics of $\mathrm{NH}_{4}-\mathrm{N}$ concentrations in soils.

because of nitrification was more pronounced in ZAF and ZBAF than in CF (Figure 3). The decrease in exchangeable $\mathrm{NO}_{3}-\mathrm{N}$ concentration in ZAF and ZBAF is probably because of the retention of $\mathrm{NH}_{4}^{+}$on the zeolite, which decreased the availability of $\mathrm{NH}_{4}^{+}$for nitrification. The concentration of both exchangeable and water-soluble $\mathrm{NO}_{3}-\mathrm{N}$ decreased gradually after 6 weeks. Eighteen weeks afterwards, the exchangeable $\mathrm{NO}_{3}-\mathrm{N}$ concentration in ZAF and ZBAF was $3.16 \%$ and $19.87 \%$ higher than in $\mathrm{CF}$, and the water-soluble $\mathrm{NO}_{3}-\mathrm{N}$ concentration in ZAF and ZBAF were $1.32 \%$ and $27.12 \%$ higher, respectively, than in CF.

Clinoptilolite zeolite has been used to reduce $\mathrm{NH}_{3}$ emission from farm manures and as an $\mathrm{NH}_{4}^{+}$-loaded exchange fertilizer because of its high CEC [14]. NK-Z has been shown to be an excellent long-term slow-release fertilizer when applied to agricultural crops. In loamy sand ( $6 \%$ clay), the decrease in $\mathrm{NO}_{3}^{-}$leaching by A-CP treatment was $30 \%$ more than that by compound fertilizer treatment [12]. Perrin hypothesized that A-CP re-

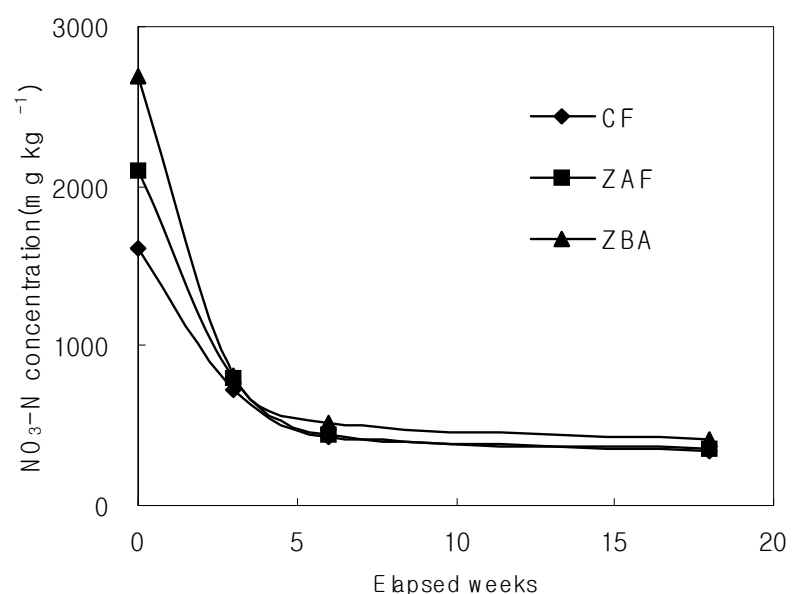

(a)

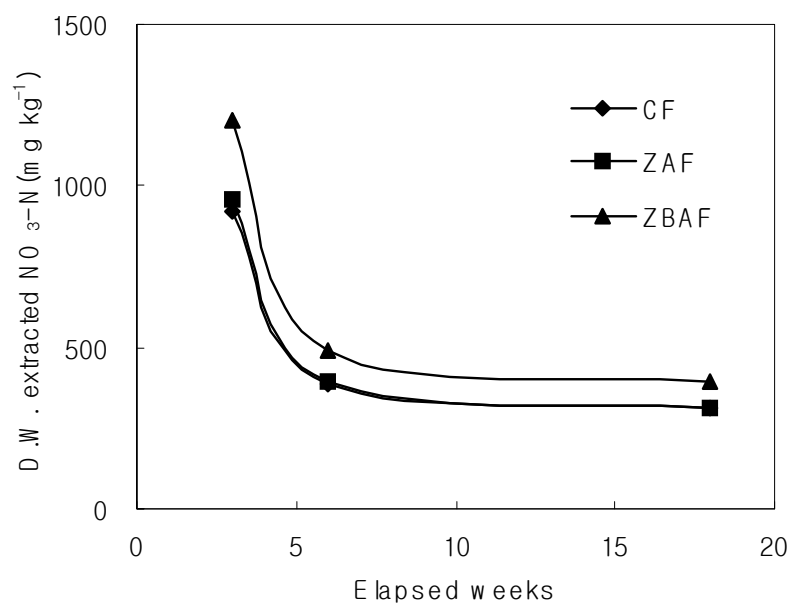

(b)

Figure 3. The dynamics of $\mathrm{NO}_{3}-\mathrm{N}$ concentrations in soils.

duced $\mathrm{N}$ leaching while increasing N-use efficiency compared to compound fertilizer [4]. However, the experiment was terminated after approximately 4 weeks, and they did not collect data pertaining to the last stage of crop growth. In our experiment, the $\mathrm{N}$ concentrations were estimated throughout the growth period of crops, and hence, we could observe the constantly changing trend of $\mathrm{N}$ concentration.

Natural zeolite can be used both as a carrier of nutrients (e.g., $\mathrm{NH}_{4}^{+}$and $\mathrm{K}^{+}$) as well as a medium of free exchangeable nutrient ions. Some natural zeolites contain considerable amounts of exchangeable $\mathrm{K}^{+}$that can enhance plant growth. Only a few studies have compared the $\mathrm{K}$ leaching from $\mathrm{K}$-saturated clinoptilolite and $\mathrm{KNO}_{3}$, pointing out the advantages of the zeolite as and slowrelease fertilizers [15]. In this experiment, the plot of $\mathrm{K}$ concentrations is shown in Figure 4. Both exchangeable and water-soluble $\mathrm{K}$ concentration decreases sharply in the first 3 weeks and stabilize thereafter. Despite the higher $\mathrm{K}^{+}$retention, the release pattern of ZAF and ZBAF is similar to that in $\mathrm{CF}$, but at the later stage, i.e., 




(a)

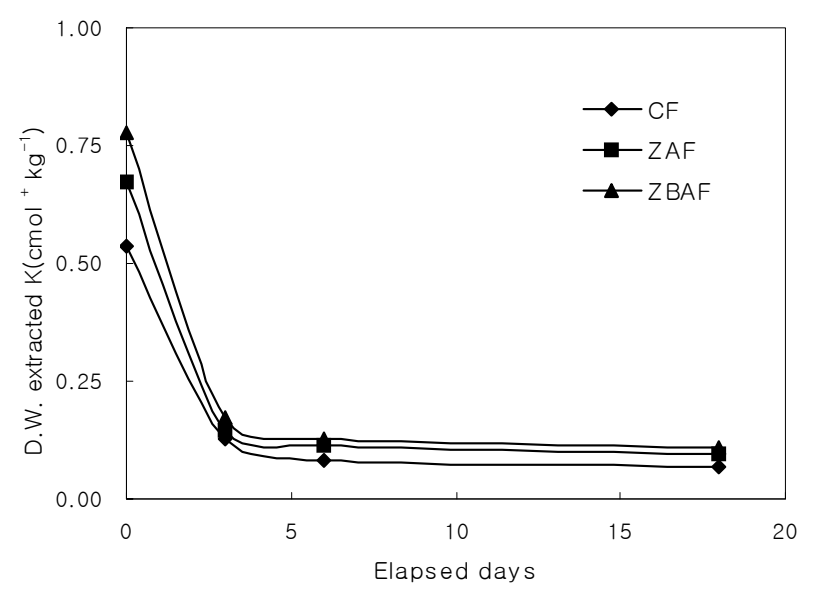

(b)

Figure 4. The dynamics of $K$ concentrations in soils.

18 weeks after transplanting, the exchangeable $\mathrm{K}$ concentrations were $12.85 \%$ and $34.08 \%$ higher and the water-soluble $\mathrm{K}$ were $39.87 \%$ and $58.37 \%$ higher, respectively, than that of CF. The K concentrations in ZAF and ZBAF were higher than that in $\mathrm{CF}$ on each of the investigation days, which indicate that NK-Z as a kind of slow-release fertilizer can maintain the high level of $K$ throughout the growth period until the final stage of plant development.

Unlike compound fertilizers, ZAF and ZBAF provided controlled release of available $\mathrm{N}$ and $\mathrm{K}$, and thus can serve as slow-release fertilizers. The slow release of $\mathrm{N}$ and $\mathrm{K}$ from $\mathrm{NK}-\mathrm{Z}$ at late stage was probably due to the diffusion and cation exchange [16], processes that control the release of $\mathrm{N}$ and $\mathrm{K}$ from $\mathrm{NK}-\mathrm{Z}$. According to the results above, we also suggest that $\mathrm{NK}-\mathrm{Z}$ can be used as slow-release fertilizers because of its long-lasting nutrient-keeping ability.

\section{Conclusion}

Many studies have been conducted to develop nitrogen best management practices (BMPs) to increase $\mathrm{N}$ utilization efficiency and to reduce $\mathrm{N}$ losses via leaching or volatilization. Zeolite has been used to reduce $\mathrm{NH}_{3}$ emission from farm manures and as $\mathrm{NH}_{4}^{+}$-loaded exchange fertilizer because of its high CEC [4,14].

In this study, we indicated that $\mathrm{NK}-\mathrm{Z}$ can maintain the requisite $\mathrm{N}$ and $\mathrm{K}$ levels during the entire period of crop growth compared with the compound fertilizer. Kale grown in soil applied with NK-Z assimilated significantly higher levels of $\mathrm{Na}, \mathrm{Mg}$, and $\mathrm{K}$ than kale grown in soil applied with $\mathrm{CF}$. According to the result of ZAF and ZBAF, we indicated that NK-Z as basal fertilizer and additional fertilizer was more effective on crop growth. That means NK-Z, not as a compound fertilizer adjunct agent, can be applied into soil instead of compound fertilizer. NK-Z can not only be used as a slow-release fertiliser for sustaining plant growth and also provide a nutrient supply that is high enough to sustain suitable plant development. Furthermore, the use of NK-Z provides a long-lasting reservoir of nutrients, which reduces the need of adding fertilization while achieving better crop performance. Another important advantage is that NK-Z as additional fertilizer can be added into soil before seedling transplanting because of their slow-release character, which can reduce lots of labour force for the application of additional fertilizer. The product is environmentally safe as well. Unlike the commonly used fertilizers, the use of NK-Z can dramatically reduce the loss of nutrients to ground water and the environment.

\section{Acknowledgements}

This study was supported by the Technology Development Program for Agriculture and Forestry, Ministry for Food, Agriculture, Forestry and Fisheries, Republic of Korea.

\section{REFERENCES}

[1] E. Polat, M. Karaca, H. Demir and N. Onus, "Use of Natural Zeolite (Clinoptilolite) in Agriculture," Journal of Fruit and Ornamental Plant Research, Vol. 12, 2004, pp. 183-189.

[2] D. W. Ming and F. A. Mumpton, "Zeolites in Soils," In: J. B. Dixon and S. B. Weed, Eds., Minerals in Soil Environments, 2nd Edition, Soil Science Society of America, Madison, 1989, pp. 874-911.

[3] A. K. Bansiwa, S. S. Rayalu, N. K. Labhasetwar, A. A. Juwarkar and S. Devotta, "Surfactant-Modified Zeolite as a Slow Release Fertilizer for Phosphorus," Journal of Agricultural and Food Chemistry, Vol. 54, No. 13, 2006, pp. 4773-4779.

[4] T. S. Perrin, D. T. Drost, J. L. Boettinger and J. M. Norton, "Ammonium-Loaded Clinoptilolite: A Slow-Release Nitrogen Fertilizer for Sweet Corn," Journal of Plant $\mathrm{Nu}$ trition, Vol. 21, No. 3, 1998, pp. 515-530. 
http://dx.doi.org/10.1080/01904169809365421

[5] E. Lichtenberg and L. S. Shapiro, "Agriculture and Nitrate Concentrations in Maryland Community Water System Wells," Journal of Environmental Quality, Vol. 26, No. 1, 1997, pp. 145-153.

[6] T. S. Perrin, D. T. Drost, J. L. Boettinger and J. M. Norton, "Ammonium-Loaded Clinoptilolite: A Slow-Release Nitrogen Fertilizer for Sweet Corn," Journal of Plant Nutrition, Vol. 21, No. 3, 2008, pp. 515-530.

[7] S. W. Ritchie, J. J. Hanway and G. O. Benson, "How a Corn Plant Develops," Iowa State University of Science and Technology Cooperative Extension Service, Special Report, 1997.

[8] J. M. Bremner and C. S. Mulvaney, "Nitrogen-Total," In: A. L. Page, R. H. Miller and D. R. Keeney, Eds., Part 2. Methods of Soil Analysis, Agronomy 9, American Society of Agronomy, 1982, pp. 403-430.

[9] NIAST, "Methods of Soil Chemical Analysis, National Institute of Agricultural Science and Technology," RDA, Suwon, 2000.

[10] Y. Watanabe, F. Uchiyama and K. Yoshida, "Compositional Changes in Spinach (Spinacia oleracea L.) Grown in the Summer and in the Fall," Journal of Japanese Society of Horticulture, Science, Vol. 62, 1994, pp. 889-895.

[11] K. Torri, "Utilization of Natureal Zeolite in Japan," In: L. B. Sand and F. A. Mumpton, Eds., Natural zeolites: Occurrence, Properties, Use, Pergamon, Elmsford, 1978, pp.
441-450.

[12] M. D. Lewis, F. D. Moore and K. L. Goldsberry, “Ammonium-Exchanged Clinoptilolite and Granulated Clinoptilolite with Urea as Nitrogen Fertilizers," In: W. G. Pond and F. A. Mumpton, Eds., Zeo-Agriculture: Use of Natural Zeolites in Agriculture and Aquaculture. Westview Press, Boulder, 1984, pp. 105-111.

[13] D. W. Ming and J. L. Boettinger, "Zeolites in Soil Environments," Reviews in Mineralogy and Geochemistry, Vol. 45, No. 1, 2001, pp. 323-345. http://dx.doi.org/10.2138/rmg.2001.45.11

[14] M. Amon, M. Dobeic, R. W. Sneath, V. R. Philips, T. H. Mis-selbrook and B. E. Pain, "A Farm-Scale Study on the Use of Clinoptilolite Zeolite and De-Odorase for Reducing Odor and Ammonia Emissions from Broiler Houses," Bioresearches Technology, Vol. 61, 1997, pp. 229-237.

[15] D. R. Hershey, J. L. Paul and R. M. Carlson, "Evaluation of Potassium-Enriched Clinoptilolite as a Potassium Source for Potting Media," Horticultural Science, Vol. 15, 1980, pp. 87-89.

[16] D. W. Ming, D. J. Barta, D. C. Golden, C. Galindo and D. L. Henninger, "Zeoponic Plant-Growth Substrates for Space Applications," In: D. W. Ming and F. A. Mumpton, Eds., Natural Zeolites: Occurrences, Properties, Use, International Committee on Natural Zeolites, Brockport, 1995, pp. 505-513. 